\title{
Gemcitabine and docetaxel as first-line treatment for advanced urothelial carcinoma: a phase II study
}

\author{
A Ardavanis*,', D Tryfonopoulos', A Alexopoulos', C Kandylis', G Lainakis' and G Rigatos' \\ IIst Department of Medical Oncology, St Savas Anticancer Hospital, 171. Alexandras Avenue, I1522 Athens, Greece
}

The purpose of the study was to investigate the toxicity and efficacy of the combination of gemcitabine and docetaxel in untreated advanced urothelial carcinoma. Patients with previously untreated, locally advanced/recurrent or metastatic urothelial carcinoma stage-IV disease were eligible. Patients with Performance status: PS ECOG $>3$ or age $>75$ years or creatinine clearance $<50 \mathrm{ml} \mathrm{min}^{-1}$ were excluded. Study treatment consisted of docetaxel $75 \mathrm{mg} \mathrm{m}^{-2}$ (day 8) and gemcitabine $1000 \mathrm{mg} \mathrm{m}^{-2}($ days $1+8)$, every 21 days for a total of six to nine cycles. A total of 31 patients with urothelial bladder cancer, 25 men and six women, aged 42-74 (median 64) years were enrolled. The majority of patients had a good PS (5I.6\%; PS 0). In all, 15 (48.3\%) patients had locally advanced or recurrent disease only and 16 (54.8\%) presented with distant metastatic spread, with multiple site involvement in 22.5\%. Toxicity was primarily haematologic, and the most frequent grade 3-4 toxicities were anaemia II (6.7\%) thrombocytopenia eight (4.9\%), and neutropenia 45 (27.6\%), with 10 (6.1\%) episodes of febrile neutropenia. No toxic deaths occurred. A number of patients had some cardiovascular morbidity (38.7\%). Nonhaematological toxicities except alopecia (29 patients) were mild. Overall response rate was $51.6 \%$, including four complete responses (12.9\%) and 12 partial responses (38.7\%), while a further five patients had disease stabilisation (s.d. 16.1\%). The median time to progression was 8 months ( $95 \% \mathrm{Cl} 5.1-9.2$ months) and the median overall survival was 15 months ( $95 \%$ Cl | I.2- 18.5 months), with I-year survival rate of $60 \%$. In conclusion, this schedule of gemcitabine and docetaxel is very active and well tolerated as a first-line treatment for advanced/relapsing or metastatic urothelial carcinoma. Although its relative efficacy and tolerance as compared to classic MVAC should be assessed in a phase III setting, the favourable toxicity profile of this regimen may offer an interesting alternative, particularly in patients with compromised renal function or cardiovascular disease. British Journal of Cancer (2005) 92, 645-650. doi:I0.1038/sj.bjc.6602378 www.bjcancer.com

Published online I February 2005

(c) 2005 Cancer Research UK

Keywords: gemcitabine; docetaxel; bladder cancer; transitional cell carcinoma

Although advanced urothelial carcinoma is a common and relatively chemosensitive neoplasm, it still remains a fatal disease. Over the last 10 years or so chemotherapy of advanced urothelial tumours has focused on cisplatin-based combinations such as cisplatin-methotrexate-vinblastine (CMV), or methotrexatevinblastine-adriamycin-cisplatin (M-VAC) (von der Maase, 2002). Response rates with standard cisplatin-based combination chemotherapy range from 40 to $70 \%$; however, approximately $50 \%$ of all patients will develop metastasis, and recent studies indicate that the disease-free long-term (5-year) survival rate is only about 4\% (Sternberg et al, 1989; Loehrer et al, 1992; Saxman et al, 1997). Standard therapy with M-VAC offers a moderate median survival of 1 year; however, it is achieved at the expense of major toxicities, including myelosuppression, nausea, vomiting and nephrotoxicity that often limit its use to patients with normal renal function and adequate performance status (Vaughn, 1999). A recent phase III study has indicated that the combination of gemcitabine/cisplatin could replace the standard of care M-VAC (von der Maase et al, 2000; Hussain et al, 2002; de Wit, 2003; Raghavan, 2003) since the

*Correspondence: Dr A Ardavanis; E-mail: ardavanis@yahoo.com Received 13 August 2004; revised I December 2004; accepted 2 December 2004; published online I February 2005 efficacy was similar in the two regimens with respect to response, time to progressive disease and overall survival; however, toxicity was significantly less in the gemcitabine/cisplatin arm (von der Maase et al, 2000). Owing to the discouraging long-term survival data for M-VAC and gemcitabine/cisplatin, attempts at minimising toxicity and maintaining current median survival times are recognised as important considerations in patient management since palliation appears to be a current goal for urothelial cancer.

Therefore, research is now focusing on new regimens including a series of agents that may improve the efficacy of established therapies, while also being effective in the subgroups of patients in which cisplatin-based regimens are contraindicated. Recent studies have indicated that the taxanes (docetaxel and paclitaxel) have significant antitumour activity as single agents (Roth et al, 1994; Dreicer et al, 1996; McCaffrey et al, 1997; Papamichael et al, 1997), or when administered in combination with other drugs (Redman et al, 1998; Zielinski et al, 1998; Bajorin et al, 2000; Dreicer et al, 2000; Hussain et al, 2001), in urothelial cancer. The majority of these new agents have demonstrated synergy when used in combination with a platinum salt showing encouraging response rates of up to $50 \%$ and median survival times of $9-14.3$ months are reported across a range of combinations (Redman et al, 1998; Zielinski et al, 1998; von der Maase et al, 1999; Dreicer et al, 2000; Kaufman et al, 2000a; Lorusso et al, 2000; Small et al, 2000). 
We have therefore decided to investigate the efficacy and toxicity of the combination of docetaxel and gemcitabine in chemonaive patients with locally advanced or metastatic urothelial carcinoma.

\section{PATIENTS AND METHODS}

\section{Patient selection}

This was a phase II study in patients with histologically confirmed advanced urothelial cancer. Patients with locally advanced or metastatic cancer of the urothelial tract with transitional cell histologies, and with evidence of measurable or evaluable disease were eligible. No previous chemotherapy for recurrent disease was allowed. Previous neoadjuvant or adjuvant treatment was allowed as long as there was at least a 12-month treatment-free interval and gemcitabine was not part of the previous chemotherapy combination (previous treatment with docetaxel as part of adjuvant or neoadjuvant chemotherapy was allowed provided $\geqslant 12$ months had passed).

Patients with other malignant tumour or tumour history, except for nonmelanoma skin cancer or radically excised in situ carcinoma of the uterine cervix were excluded. Patients aged $>75$ years were excluded, as were patients with severe chronic obstructive lung disease. Also excluded were patients with known CNS metastases, patients who were pregnant or those with creatinine clearance less than $50 \mathrm{ml} \mathrm{min}^{-1}$, WBC $<3.5 \times 10^{9} \mathrm{l}^{-1}$, neutrophil count $<1.5 \times 10^{9} 1^{-1}$ or platelet count $<100 \times 10^{9} 1^{-1}$ within the 2 weeks preceding the start of the study. Furthermore, patients with active infections or other serious underlying medical or mental conditions, which would impair their ability to receive protocol treatment, could not participate.

The study was conducted according to the Declaration of Helsinki and the guidelines for Good Clinical Practice. The local ethics committees approved the protocol and informed consent was obtained from all patients prior to study entry.

\section{Treatment schedule}

Treatment was administered on an outpatient basis. Gemcitabine $1000 \mathrm{mg} \mathrm{m}^{-2}$ was administered by an intravenous infusion over $30 \mathrm{~min}$ on days 1 and 8 , while docetaxel $\left(75 \mathrm{mg} \mathrm{m}^{-2}\right)$ was administered as an intravenous infusion over $1 \mathrm{~h}$ on day 8 . Treatment was repeated every 21 days. Standard antiemetic premedication and treatment was administered. Haematopoietic growth factors were not used prophylactically. Supportive care, including blood transfusions, analgesics and antiemetics, was administered as appropriate. Patients received a total of six cycles unless disease progression or unacceptable toxicity occurred. Patients who showed disease stabilisation or response were scheduled to receive the same regimen for up to nine full chemotherapy cycles.

\section{Dose modifications for adverse events}

Toxicity was evaluated before each treatment cycle according to the National Cancer Institute Common Toxicity Criteria (NCI CTC version 2.0). Dosage adjustments were made before each treatment based on blood counts, renal and liver function tests and other toxicity. Once the dose of chemotherapy was reduced, they were not re-escalated. Both drugs were given on schedule providing that ANC was $\geqslant 1.5 \times 10^{9} 1^{-1}$ and the platelet count $\geqslant 100 \times 10^{9}-1^{-1}$. For ANC of $<1.5 \times 10^{9} 1^{-1}$ on day 1 , treatment was delayed for 1 week, haematopoietic growth factor $(\mathrm{G}-\mathrm{CSF}) \times 5$ days were given, and the next cycle began on day 28 instead of day 21 . If platelet counts were $<75 \times 10^{9} 1^{-1}$ for 1 week, the next cycles were to be given every 4 weeks. If platelets were $<75 \times 10^{9} 1^{-1}$ for 2 weeks, then the next cycles were to be given every 4 weeks with the doses of both drugs reduced by $25 \%$. If ANC did not recover above $1.5 \times 10^{9} 1^{-1}$ for 3 weeks or if platelets were $<75 \times 10^{9} 1^{-1}$ for $>2$ weeks, treatment was discontinued and the patient was taken off study. In case of haematological toxicity on day 8 (AN$\mathrm{C}<1.5 \times 10^{9} 1^{-1}$, PLT $<100 \times 10^{9} 1^{-1}$ ), the gemcitabine treatment of day 8 was delayed for 1 week. The same dose was then administered on day 15 , and the cycle was repeated every 28 days instead of 21 days. In case of persistent haematological toxicity on day 15 , the gemcitabine day 8 treatment was omitted and chemotherapy was repeated on day 21 with a $25 \%$ dose reduction for both drugs. In case of grade 3-4 neutropenia during a chemotherapy cycle, G-CSF $\times 5$ days was to be used prophylactically for the next cycles, days 10-14.

\section{Evaluation of response}

Baseline evaluation prior to chemotherapy initiation included a complete past medical history, thorough physical examination, a chest X-ray followed by CT scan of the chest if CXR was abnormal, a CT scan of the abdomen and pelvis, bone scan, as well as complete blood counts, renal and liver function tests. During treatment, renal and liver function tests were carried out before each cycle on day 1 , and complete blood count was carried out on days 1 and 8 of each cycle. Complete blood counts were also obtained on day 14 of the first course in order to assess nadir WBC and PLT.

Restaging and tumour measurements were performed after three cycles and following completion of treatment, that is, after six or nine cycles of chemotherapy, unless earlier evaluation was required. Dose intensity was defined as the total amount of the drug given $\left(\mathrm{mg} \mathrm{m}^{-2}\right)$ divided by the number of weeks. All patients were analysed on an intention-to-treat basis. Therefore, all patients, even those receiving only one cycle of chemotherapy, were analysed for toxicity, response, duration of response and survival. Patients who discontinued treatment before an evaluation was performed were rated as nonresponders. Standard WHO criteria were used to assess response.

Treatment was discontinued if disease progression was documented, or when unacceptable toxicity or conditions requiring therapeutic intervention not permitted by the protocol occurred. Also, treatment was discontinued when the patient wished to withdraw consent, or in any other situation where, in the opinion of the investigator continued participation in the study would not be in the best interest of the patient. All adverse events resulting in discontinuation of study drug were followed closely until resolution or stabilisation. Follow-up disease evaluation was performed regularly at 3 monthly intervals after treatment completion till death. Progression or disease relapse, surgical procedures (cystectomy, etc.), site of relapse and cause of death were noted.

\section{Statistical analysis}

The study was a nonrandomised, phase II study. The primary end point was objective response rate and secondary end points were overall survival, TTP and toxicity. The sample size was calculated on the assumption that a $40 \%$ response rate would be detected and the minimum acceptable response rate would be $20 \%$. According to Simon's two-stage design, a sample of 18 patients was required in the first step. If a minimum of five responses were observed, a total of 33 patients would be accrued. Thereby, if at least 11 responses occurred, the probability of accepting a treatment with a real response rate of less than $20 \%$ would be $5 \%$. On the other hand, the risk of rejecting a treatment (at the second stage) with a response rate of more than $40 \%$ would be $20 \%$. Time to disease progression (TTP) was calculated from the initiation of treatment to the date progression of the disease was firstly documented (patients who discontinued their treatment for any reason or died 
from probable disease - related causes were considered, at that time, as having disease progression). Survival was calculated from initiation of treatment to the date of last contact or to the date of death. The Kaplan-Meier method (Kaplan and Meier, 1958) was used to calculate TTP and survival curves and exact CIs (Lentner, 1982) were used to determine the $95 \%$ upper and lower confidence limits of response rate. Data analysis was performed using SPSS 10.5 (SPSS, Inc, Chicago, IL, USA).

\section{RESULTS}

\section{Patient characteristics}

Between May 2000 and April 2002, 31 patients with locally advanced/relapsed or metastatic urothelial carcinoma of stage IV were accrued to this single-institution study. Two patients could not be evaluated for efficacy end points since they were lost to follow-up after two and three cycles, respectively. Final data analysis was performed in May 2003, 12 months after accrual of the last patient. The main patient baseline characteristics are summarised in Table 1. The majority of patients had ECOG Performance Status of 0 or 1 ; only $9.7 \%$ of the patients had a PS of 2. A percentage of the patients $(12 ; 38.7 \%)$ had some type of coexisting cardiovascular disease.

Table I Patient characteristics

\begin{tabular}{|c|c|c|}
\hline \multirow[b]{2}{*}{ Characteristic } & \multicolumn{2}{|c|}{ Patients } \\
\hline & No. & $\%$ \\
\hline Number of patients registered & 31 & \\
\hline \multicolumn{3}{|l|}{ Age, years } \\
\hline Median & 64 & \\
\hline Range & $42-74$ & \\
\hline \multicolumn{3}{|l|}{ Sex } \\
\hline Male & 25 & 80.6 \\
\hline Female & 6 & 19.4 \\
\hline \multicolumn{3}{|l|}{ Performance Status ECOG } \\
\hline 0 & 16 & 51.6 \\
\hline I & 12 & 38.7 \\
\hline 2 & 3 & 9.7 \\
\hline \multicolumn{3}{|l|}{ Cardiovascular comorbidity } \\
\hline Hypertension (controlled) & 18 & 58 \\
\hline Atherosclerosis & 11 & 35.5 \\
\hline Coronary artery disease & 7 & 22.5 \\
\hline Total (one or a combination of the above) & 12 & 38.7 \\
\hline \multicolumn{3}{|l|}{ Histological types } \\
\hline Transitional cell carcinoma & 31 & 100 \\
\hline \multicolumn{3}{|l|}{ Previous treatment } \\
\hline Surgery & 16 & 51.6 \\
\hline Chemotherapy & 8 & 25.8 \\
\hline Radiotherapy & 8 & 25.8 \\
\hline \multicolumn{3}{|l|}{ Sites of disease } \\
\hline Locally advanced disease & 10 & 32.2 \\
\hline Locally recurrent & 5 & 16.1 \\
\hline Metastatic disease & 16 & 51.6 \\
\hline Lymph nodes & 7 & 22.5 \\
\hline Bones & 5 & 16.1 \\
\hline Lung & 9 & 29.0 \\
\hline Liver & 7 & 22.5 \\
\hline Multiple site involvement & 7 & 22.5 \\
\hline Local and distant disease & 8 & 25.8 \\
\hline
\end{tabular}

Note: patients can have more than one site of metastatic disease.
More than half of the patients presented with distant metastases, while among the remaining 15 patients, five (16.1\%) had locally recurrent and $10(32.2 \%)$ had de novo locally advanced disease. The total number of patients with disease in the pelvis was 20 $(64.5 \%)$. Eight $(25.8 \%)$ patients presented both local and distant disease, with multiple site involvement in seven (22.5\%) patients. Study treatment was administered in all cases as first-line therapy; however, while 14 patients had not previously received any therapeutic manipulation, 16 patients had prior surgery, eight patients were exposed to prior adjuvant/neoadjuvant chemotherapy, or radiotherapy $(n=8)$ to the pelvis. Eight patients had previously received chemotherapy in the adjuvant or neoadjuvant setting; two with M-VAC, one with MVEC, two with CMV, one with CisCA and two with carboplatin/gemcitabine.

\section{Study treatment administration}

All patients were included in the analysis of treatment administration and toxicity. A total of 163 treatment cycles were administered. Patients received a median number of six cycles of chemotherapy, with a range of one to nine cycles. Of the 31 patients analysed, 20 patients $(64.5 \%)$ completed at least six cycles of treatment, and six (19.4\%) received seven to nine cycles. Reasons for treatment discontinuation included disease progression or recurrence in eight patients. Dosage of study drugs was modified mainly due to haematological toxicity. A total of 20 patients received G-CSF. Gemcitabine doses were reduced (dose actually taken $\leqslant 90 \%$ of planned dose) or omitted on day 1 in 15 $(9.2 \%)$ cycles and on day 8 in nine $(5.5 \%)$ courses. The median delivered dose intensity was $599.4 \mathrm{mg} \mathrm{m}^{-2}$ week $^{-1}$ (range: 580 $633 \mathrm{mg} \mathrm{m}^{-2}$ ) for gemcitabine, and $20.2 \mathrm{mg} \mathrm{m}^{-2}$ week $^{-1}$ for docetaxel (range: $15-25 \mathrm{mg} \mathrm{m}^{-2}$ ), with a mean relative dose intensity of 90 and $95 \%$ for gemcitabine and docetaxel, respectively. All five patients with bone metastasis received pamidronate $90 \mathrm{mg}$ every 3-4 weeks for 6-12 months to achieve palliation of skeletal symptoms.

\section{Toxicity}

All patients $(n=31)$ were evaluable for toxicity. Toxicity was primarily haematologic with neutropenia being the most prominent with 33 incidences of grade 3 and 12 of grade 4 . There were 10 episodes of grade 4 febrile neutropenia requiring hospitalisation. No toxic deaths occurred. Nonhaematological toxicities were mild, 23 episodes of hypersensitivity and/or cutaneous reactions grade 3/ 4. Alopecia occurred in nearly all patients. Grade 3-4 toxicity data according to the NCI CTC criteria are summarised in Table 2.

Table 2 Toxicity (cycles $n=163$ )

\begin{tabular}{|c|c|c|c|c|}
\hline \multirow[b]{2}{*}{ Toxicity } & \multicolumn{2}{|c|}{ Grade 3} & \multicolumn{2}{|c|}{ Grade 4} \\
\hline & No. & $\%$ & No. & $\%$ \\
\hline Anaemia & || & 6.7 & 0 & 0 \\
\hline Neutropenia & 33 & 20.2 & 12 & 7.4 \\
\hline Thrombocytopenia & 6 & 3.7 & 2 & 1.2 \\
\hline Diarrhoea & 10 & 6.1 & 0 & 0 \\
\hline Febrile neutropenia & 0 & 0 & 10 & 6.1 \\
\hline Cutaneous & || & 6.7 & 3 & 1.8 \\
\hline Hypersensitivity & 9 & 5.5 & 0 & 0 \\
\hline Fever & 9 & 5.5 & 0 & 0 \\
\hline Oedema & 8 & 4.9 & 0 & 0 \\
\hline Mucositis & 7 & 4.3 & I & 0.6 \\
\hline
\end{tabular}

Percentages expressed per cycle. 


\section{Response and survival}

From a total of 31 patients entered in the study, two were lost to follow-up, however, due to the intention-to-treat-analysis; all of the patients enrolled were included in the main analysis of the response rate; Table 3. Four patients achieved a complete response (CR $12.9 \%$ ) and 12 patients achieved a partial response (PR $38.7 \%$ ), giving an overall response (OR) of $51.6 \%$. In addition, five patients achieved disease stabilisation (s.d. 16.1\%), while eight patients had progressive disease (PD 25.8\%). Responses were seen at all sites of measurable disease. Skeletal sites were not included in the response assessment given the concurrent use of pamidronate, although in all five patients with bone metastases a symptomatic palliation as well as evidence of stabilization (three patients) or bone healing (two patients) were noted.

With a median follow-up of 23 months (range 12-36 months), 26 patients have died $(83.9 \%)$. The median time to progression (TTP) was 8.0 months (range $0.0-20.0,95 \%$ CI: $5.1-9.2$ ). With five patients still alive, two at $36+$ months the median survival has not been reached; 15 months (range 2.0-36.0+, 95\% CI: 11.2-18.5). The estimated 1-year survival rate was $60 \%$ (Figure 1).

\section{DISCUSSION}

In this phase II trial, the combination of gemcitabine and docetaxel was well tolerated and effective as first-line treatment for metastatic urothelial carcinoma. The OR rate of $51.6 \%$ and a median overall survival of 15 months were similar to a series of rates achieved with combinations including cisplatin/gemcitabine (Moore et al, 1999; von der Maase et al, 1999; Kaufman et al,

Table 3 Response and survival $(n=31)$

\begin{tabular}{lcc}
\hline & No. & $\%$ \\
\hline Complete response (CR) & 4 & 12.9 \\
Partial response (PR) & 12 & 38.7 \\
Stable disease (SD) & 5 & 16.1 \\
Progressive disease (PD) & 8 & 25.8 \\
Overall response (OR) & 16 & 51.6 \\
& & \\
Time to progression & Median (months) & $\mathbf{9 5 \%} \mathbf{C l}$ \\
Overall survival & 8.0 & $5.1-9.2$ \\
\hline
\end{tabular}

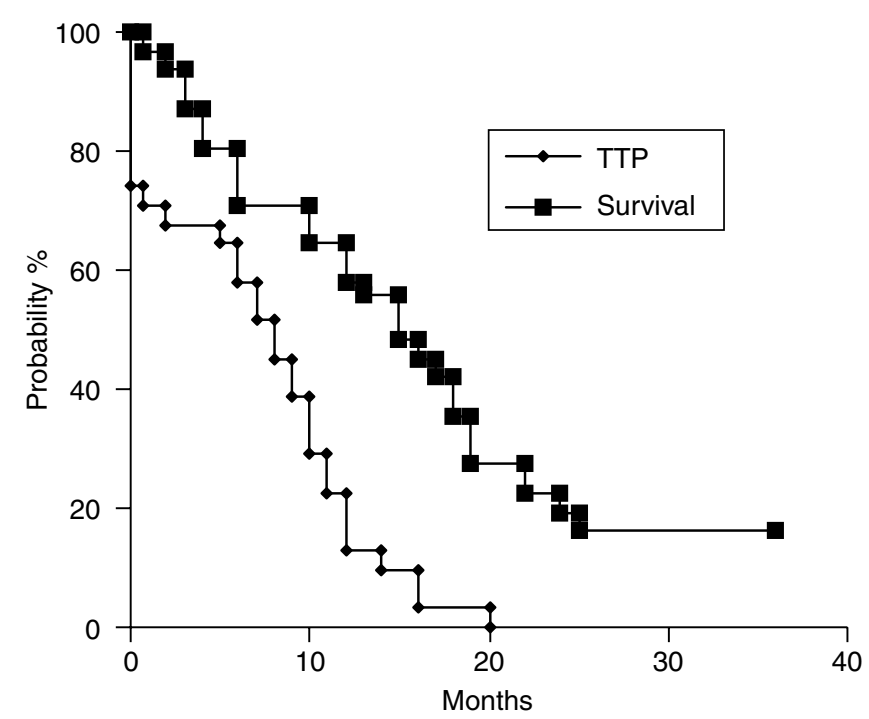

Figure I Time to progression (TTP) and overall survival. 2000a; Lorusso et al, 2000) or cisplatin/docetaxel (Sengelov et al, 1998; Dimopoulos et al, 1999).

For many years the gold standard treatment for urothelial cancer has been the M-VAC regimen. However, with the results of the recent randomised comparison with gemcitabine/cisplatin, options are rapidly changing (von der Maase, 2002). It has been realised that using alternative two or three drug combination regimens principally utilising platinum salts, efficacy with respect to disease-free survival, time to progression and overall survival can be maintained while reducing not only the toxicity but also improving the overall quality of life (Sternberg, 2000). There are, however, concerns with the use of platinum salts, as the toxicities are not insignificant especially considering that long-term survival remains relatively poor and the major clinical benefit for the move away from M-VAC is palliative rather than curative. As many patients are unable to tolerate cisplatin-based therapy, carboplatin has been investigated as an alternative. Although it has found its way into clinical use due to a low toxicity profile, when compared to standard M-VAC, trials indicate disappointing single-agent response rates (Medical Research Council, 1987) and shorter median survival when combined with paclitaxel (Redman et al, 1998; Vaughn et al, 1998). In the few studies that have been published, the combination of carboplatin/gemcitabine appears to be inferior to that obtained with gemcitabine/cisplatin (Stadler, 2002; von der Maase, 2002).

Although few studies have investigated the combination of gemcitabine/paclitaxel, the so far reported small phase II trials have indicated that the combination is effective and well tolerated. In a phase II study using $2500-3000 \mathrm{mg} \mathrm{m}^{-2}$ gemcitabine and $150 \mathrm{mg} \mathrm{m}^{-2}$ paclitaxel every 2 weeks in M-VAC-pretreated patients, Marini et al (1999) reported an overall response rate of $62 \%$ and complete response of $24 \%$. Neutropenia grade $3 / 4$ was noted in $43 \%$ and neurotoxicity in $6 \%$ of the patients. In the studies by Sternberg et al (2000) and Kaufman et al (2000b), combination of $3000 \mathrm{mg} \mathrm{m}^{-2}$ gemcitabine and $150 \mathrm{mg} \mathrm{m}^{-2}$ paclitaxel was delivered every 2 weeks in previously treated and chemonaive patients, respectively. They reported OR rates of 39 and 64\% (CR 25\%), respectively. In a further study by Meluch et al (2001), gemcitabine was administered on days 1,8 and 15 at $1000 \mathrm{mg} \mathrm{m}^{-2}$ and paclitaxel at $200 \mathrm{mg} \mathrm{m}^{-2}$ on day 1 every 21 days. In all, 29 of 54 eligible patients responded (54\%), 22 in the group of 42 patients with no prior chemotherapy, with a CR rate of $7 \%$. Grade 3/4 neutropenia was observed in $46 \%$ and grade $3 / 4$ thrombocytopenia was seen in $13 \%$ of the patients.

As for the combination of gemcitabine/docetaxel in urothelial cancer, only one report has been published in which three out of five patients developed pulmonary toxicity in a phase I setting (Dunsford et al, 1999). In our patients no clinically significant toxicity was detected, although there might have been some subclinical decrease of respiratory reserve. However, none of our patients had a history of lung disease except for smoking, continued or in the past, in 19 patients. Nevertheless, the risk of pulmonary toxicity must be kept in mind when treating patients with this combination. The absence of cardiovascular complications in this population, although not expected with the gemcitabine/docetaxel combination, has to be emphasised, since a significant proportion of patients presented with some heart or arterial disease.

To our knowledge, the present clinical trial represents one of the first phase II studies using this combination showing an OR of $51.6 \%$ and CR of $12.9 \%$ comparable with other studies in chemotherapy naïve patients, albeit mainly using the combination of gemcitabine/paclitaxel. Moreover, one recent phase II study has investigated the combination of gemcitabine/docetaxel in TCC with a different schedule and found a lower objective response rate (33.3\%) but a similar overall (52 weeks) survival (Gitliz et al, 2003).

The taxanes are primarily being studied due to their efficacy in previously pretreated patients. Incorporation of taxanes as firstline treatment for advanced urothelíal carcinoma may not only 
offer an alternative to gemcitabine/cisplatin but may eventually be indicated as a first-line treatment, if equivalence to M-VAC or gemcitabine/cisplatin regimens can be confirmed by further studies. At present the choice of effective regimens needs to be addressed by more rigorous patient stratification and comparison with M-VAC or gemcitabine/cisplatin in both naïve and previously pretreated patients, while special attention should be paid towards compromised patients.

\section{REFERENCES}

Bajorin DF, McCaffrey JA, Dodd PM, Hilton S, Mazumdar M, Kelly WK, Herr H, Scher HI, Icasiano E, Higgins G (2000) Ifosfamide, paclitaxel, and cisplatin for patients with advanced transitional cell carcinoma of the urothelial tract: final report of a phase II trial evaluating two dosing schedules. Cancer 88: $1671-1678$

de Wit R (2003) Overview of bladder cancer trials in the European Organisation for Research and Treatment. Cancer 97(Suppl 8): 2120-2126

Dimopoulos MA, Bakoyannis C, Georgoulias V, Papadimitriou C, Manolopoulos LA, Deliveliotis C, Karayannis A, Varkarakis I, Aravantinos G, Zervas A, Pantazopoulos D, Foutzilas G Bamias A, Kyriakakis Z, Anagnostopoulos A, Giannopoulos A, Kosmidis P (1999) Docetaxel and cisplatin combination chemotherapy in advanced carcinoma of the urothelium: a multicentre phase II study of the Hellenic Cooperative Oncology Group. Ann Oncol 10: 1385-1388

Dreicer R, Gustin DM, See WA, Williams RD (1996) Paclitaxel in advanced urothelial carcinoma: its role in patients with renal insufficiency and as salvage therapy. J Urol 156: 1606-1608

Dreicer R, Manola J, Roth BJ Cohen MB, Hatfield AK, Wilding G (2000) Phase II study of cisplatin and paclitaxel in advanced carcinoma of the urothelium: an Eastern Cooperative Oncology Group Study. J Clin Oncol 18: $1058-1061$

Dunsford ML, Mead GM, Bateman AC, Cook T, Tung K (1999) Sever pulmonary toxicity in patients treated with a combination of docetaxel and gemcitabine for metastatic transitional cell carcinoma. Ann Oncol 10: $943-947$

Gitliz BJ, Baker C, Chapman Y, Allen HJ, Bosserman LD, Patel R, Sanchez JD, Shapiro RM, Figlin RA (2003) A phase II study of gemcitabine and docetaxel therapy in patients with advanced urothelial carcinoma. Cancer 98: $1863-1869$

Hussain M, Vaishampayan U, Du W, Redman B, Smith DC (2001) Combination paclitaxel, carboplatin, and gemcitabine is an active treatment for advanced urothelial cancer. J Clin Oncol 19: 2527-2533

Hussain M, Vaishampayan U, Smith DC (2002) Novel gemcitabinecontaining triplets in the management of urothelial cancer. Semin Oncol 29: $20-24$

Kaplan E, Meier P (1958) Nonparametric estimation from incomplete observations. J Am Stat Assoc 53: $457-481$

Kaufman D, Raghavan D, Carducci M, Levine EG, Murphy B, Aisner J, Kuzel T, Nicol S, Oh W, Stadler W (2000a) Phase II trial of gemcitabine plus cisplatin in patients with metastatic urothelial cancer. J Clin Oncol 18: $1921-1927$

Kaufman DS, Stadler WM, Carducci MA, Kuzel T, Todd M, Raghavan D, Reznikoff G, Cohen J, Smith C, Woodley S, Murphey B, Nicol S (2000b) Gemcitabine $(G)$ and paclitaxel $(P)$ every 2 weeks (GP2W): a multicenter phase II trial in locally advanced or metastatic urothelial cancer (UC). Proc Am Soc Clin Oncol 19: 341a

Lentner C (1982) 'Exact Confidence Limits for P'. In: Geigy Scientific Tables pp. 89-102. Switzerland: Ciba-Geigy

Loehrer PJ, Einhorn LH, Elson PJ, Crawford ED, Kuebler P, Tannock I, Raghavan D, Stuart-Harris R, Sarosdy MF, Lowe BA (1992) A randomized comparison of cisplatin alone or in combination with methotrexate, vinblastine and doxorubicin in patients with metastatic urothelial carcinoma: a cooperative group study. J Clin Oncol 10: 1066 - 1073

Lorusso V, Manzione L, De Vita F, Antimi M, Selvaggi FP, De Lena M (2000) Gemcitabine plus cisplatin for advanced transitional cell carcinoma of the urinary tract: a phase II multicentre trial. J Urol 164: $53-56$

Marini L, Sternberg CN, Sella A, Calabro F, Va RA (1999) A new regimen of gemcitabine and paclitaxel in previously treated patients with advanced transitional cell carcinoma. Proc Am Soc Clin Oncol 18: 346a
In conclusion, the efficacy of the gemcitabine/docetaxel regimen reported in this study coupled with the acceptable toxicity observed indicate that this combination is an interesting candidate for future comparisons with M-VAC or other gemcitabine- or cisplatin-based regimens. Furthermore, the favourable toxicity profile indicates it as an interesting alternative, particularly in patients with compromised renal function or cardiovascular disease.

McCaffrey JA, Hilton S, Mazumdar M, Sadan S, Kelly WK, Scher HI, Bajorin DF (1997) Phase II trial of docetaxel in patients with advanced or metastatic transitional-cell carcinoma. J Clin Oncol 15: 1853-1857

Medical research council (1987) A phase II study of carboplatin in metastatic transitional cell carcinoma of the bladder. Eur J Cancer 23: $375-377$

Meluch AA, Greco FA, Burris HA, O'Rourke T, Ortega G, Steis RG, Morrissey LH, Johnson V, Hainsworth JD (2001) Paclitaxel and gemcitabine chemotherapy for advanced transitional cell carcinoma (TCC) of the urothelial tract: a phase II trial of the Minnie Pearl Cancer Research Network. J Clin Oncol 19: 3018-3024

Moore MJ, Winquist EW, Murray N, Tannock IF, Huan S, Bennet K, Walsh W, Seymour L (1999) Gemcitabine plus cisplatin, an active regimen in advanced urothelial cancer: a phase II trial of the National Cancer Institute of Canada Trials Group. J Clin Oncol 17: 2876-2881

Papamichael D, Gallagher CJ, Oliver RTD, Johnson PW, Waxman J (1997) Phase II study of paclitaxel in pretreated patients with locally advanced/ metastatic cancer of the bladder and ureter. Br J Cancer 75: 606-607

Raghavan D (2003) Progress in the chemotherapy of metastatic cancer of the urinary tract. Cancer 97(Suppl 8): 2050-2055

Redman BG, Smith DC, Flaherty L, Du W, Hussain M (1998) Phase II trial of paclitaxel and carboplatin in the treatment of advanced urothelial carcinoma. J Clin Oncol 16: 1844-1848

Roth BJ, Dreicer R, Einhorn LH, Neuberg D, Johnson DH, Smith JL, Hudes GR, Schultz SM, Loehrer PJ (1994) Significant activity of paclitaxel in advanced transitional-cell carcinoma of the urothelium: a phase II trial of the Eastern Cooperative Oncology Group. J Clin Oncol 12: $2264-2270$

Saxman SB, Propert KJ, Einnhorn LH, Crawford ED, Tannock I, Raghavan D, Loehrer Sr PJ, Trump D (1997) Long-term follow-up of a phase III Intergroup study of cisplatin alone or in combination with methotrexate, vinblastine, and doxorubicin in patients with metastatic urothelial carcinoma: a cooperative group study. J Clin Oncol 15: 2564-2569

Sengelov L, Kamby C, Lund B, Engelholm SA (1998) Docetaxel and cisplatin in metastatic urothelial cancer: a phase II study. J Clin Oncol 16: $3392-3397$

Small EJ, Lew D, Redman BG, Petrylak DP, Hammond N, Gross HM, Eastham JA, Crawford ED (2000) Southwest Oncology Group Study of paclitaxel and carboplatin for advanced transitional-cell carcinoma: the importance of survival as a clinical trial end point. J Clin Oncol 18: $2537-2544$

Stadler WM (2002) Gemcitabine doublets in advanced urothelial cancer. Semin Oncol 29(Suppl 3): 15-19

Sternberg CN (2000) Gemcitabine in bladder cancer. Semin Oncol 27(Suppl 2): $31-39$

Sternberg CA, Sella A, Calabro E, Pizzocaro G, Marini L (2000) Second line chemotherapy with every 2 -week gemcitabine and paclitaxel in previously treated patients with transitional cell carcinoma. Proc Am Urol Assoc 16: 236a

Sternberg CN, Yagoda A, Scher HI, Watson RC, Geller N, Herr HW, Morse MJ, Sogani PC, Vaughan ED, Bander N, Weiselberg L, Rosado K, Smart T, Lin SY, Penenberg D, Fair WR, Whitmore Jr WF (1989) Methotrexate, vinblastine, doxorubicine and cisplatin for advanced transitional cell carcinoma of the urothelium. Efficacy and patterns of response and relapse. Cancer 64: 2448-2458

Vaughn DJ (1999) Review and outlook for the role paclitaxel in urothelial carcinioma. Semin Oncol 26(Suppl 2): 117-122

Vaughn DJ, Malkowicz SB, Zoltick B, Mick R, Ramchandani P, Holroyde C, Armstead B, Fox K, Wein A (1998) Paclitaxel plus carboplatin in advanced carcinoma of the urothelium: an active and tolerable outpatient regimen. J Clin Oncol 16: 255-260 
von der Maase H (2002) Current and future prospectives in advanced bladder cancer: is there a new standard? Semin Oncol 29(Suppl 3): $3-14$

von der Maase H, Andersen L, Crino L, Weinknecht S, Dogliotti L (1999) Gemcitabine plus cisplatin combination therapy in patients with transitional cell carcinoma of the urothelium: a phase II clinical trial. Ann Oncol 10: $1461-1465$

von der Maase H, Hansen SW, Roberts JT, Dogliotti L, Oliver T, Moore MJ, Bodrogi I, Alberts P, Knuth A, Lippert CM, Kerbrat P, Sanchez Rovira P,

Wersall P, Cleall SP, Roychowdhury DF, Tomlin I, Visseren-Grul CM, Conte PF (2000) Gemcitabine and cisplatin $v s$ methotrexate, vinblastine, doxorubicin, and cisplatin in advanced or metastatic bladder cancer: results of a large, randomized, multinational multicenter phase III study. J Clin Oncol 18: $3068-3077$

Zielinski CC, Schnack B, Grbovic M, Brodowicz T, Wiltschke C, Steger G, Pfluger H, Marberger M (1998) Paclitaxel and carboplatin in patients with metastatic urothelial cancer: results of a phase II trial. Br J Cancer 78: $370-374$ 